Nome próprio e constituição do sujeito Given name and the constitution of the subject

Bethania Mariani Universidade Federal Fluminense, Rio de Janeiro, RJ, Brasil

Resumo: Este artigo discute a relação entre constituição do sujeito e nome próprio em um duplo percurso: o da linguística e o da psicanálise.

Palavras-chave: Nome próprio. Semântica do acontecimento. Psicanálise. Sujeito.

Abstract: In this article we discuss the relationship between subject and given name in two perspectives: linguistics and psychoanalysis.

Keywords: Given name. Linguistics. Discourse analysis. Psychoanalysis. Subject. 
Entrei na vida marcado com este apelido de Saramago

sem que a familia o suspeitasse...

(José Saramago)

Vocês sempre devem prestar atenção em como se chama seu paciente.

Nunca é indiferente.

(Jacques Lacan)

Bethania

Mariani

132

\section{Alguma introdução}

Em Pequenas memórias (2006), José Saramago narra a história de seu nome próprio. Todos nós temos alguma história para contar sobre nosso nome próprio nome que nos inscreve em uma linhagem, em uma cultura, na lei. Nome que porta algum discurso que nos antecede e que nos inscreve em uma escrita, funcionando como uma marca inicial que nos especifica e nos determina com as cores do imaginário de quem nos nomeou. A história de Saramago, como todas as histórias que falam sobre o próprio do nome próprio, é bastante singular. Ao nascer, seu pai foi registrá-lo como José de Sousa, nome homônimo ao seu próprio, mas o funcionário do Registro Civil estava, como nos diz Saramago, "sob os efeitos do álcool e sem que ninguém se tivesse apercebido da onomástica fraude, decidiu, por sua conta e risco, acrescentar Saramago ao lacônico José de Sousa que meu pai pretendia que eu fosse" (SARAMAGO, 2006, p. 43). "Saramago", explica-nos Saramago, era a denominação através da qual sua família era conhecida na aldeia em que vivam no interior de Portugal; uma espécie de apelido ("alcunha") que, no caso, não era pejorativo como tantos outros atribuídos às demais famílias da região.

Assim, dessa maneira inusitada, o formidável autor português foi nomeado e portou um nome próprio descoberto apenas quando tinha sete anos ao ser matriculado na escola pública. Seu pai, por sua vez, para adequar-se ao sistema legal português, precisou acrescentar em seu próprio nome o "Saramago" de seu filho. "Suponho", conta nosso Saramago com graça, "que deverá ter sido este o único caso, na história da humanidade, em que foi o filho a dar o nome ao pai" (SARAMAGO, 2006, p. 44). Mas mesmo assim, continua o autor, por não gostar do nome "Saramago", o pai sempre deu um jeito de permanecer sendo chamado de "Sousa".

De nosso lado, podemos supor que nessa inversão - o filho dando o nome ao pai já adulto, um nome de que o pai não gostava - a transmissão 
geracional da história e a memória (do futuro) da novela da família Sousa foram renoduladas em função desse "Saramago": um significante inesperado vindo de um tabelião alcoolizado, significante marcado por uma carga imaginária vinculada ao passado de origem rural e da família.

Em nossa sociedade ocidental, cabe ao pai nomear o filho, entendendo-se o nomear, aqui, enquanto uma operação simbólica, que é extrair do Outro um significante para inseri-lo em um registro jurídico; e uma função simbólica, que é o acontecimento da nomeação em si, uma contingência (SOLLER, 1969). O que é um nome próprio, podemos nos perguntar. Qual sua função singular no processo de subjetivação? Com essas perguntas, eis aqui nosso objetivo: discutir o nome próprio e o caminho de subjetivação pelo significante.

\section{Nome próprio e constituição do sujeito}

\section{Percursos: 1}

Há várias possibilidades de pesquisa para se falar sobre o nome próprio. No âmbito dos estudos da linguagem, que remonta aos da lógica, da gramática, da retórica e da filosofia, o nome próprio deve ser situado a partir de estudos sobre o funcionamento geral dos nomes, mais especificamente em relação à questão da referência. Os nomes próprios de pessoas, em princípio, funcionariam de modo diferenciado e particularizado relativamente aos nomes comuns, uma vez que supõem, como referente, um objeto único.

Em Guimarães (2002), pode-se ler o percurso dos estudos de Mill, Frege e Russell, autores que, do campo da filosofia e da lógica, dedicam-se a verificar a especificidade do funcionamento da designação e da produção de significado dos nomes próprios. Na semântica linguística, mais particularmente, a partir da semântica do acontecimento, Guimarães (2002) faz uma afirmação que tem sua relevância para o que pretendemos discutir aqui: "o funcionamento do nome se dá no processo social de subjetivação" (p. 36). A questão da nomeação de Saramago, apresentada anteriormente, insere-se dentro desse processo social em que se inscreve socialmente um sujeito: é o sistema jurídico que dá existência, e torna visível um recém-nascido em seus passos iniciais como membro de uma dada formação social a partir da necessidade de uma nomeação feita em cartório. Um registro que o localiza em uma descendência familiar, em uma localidade geográfica e em um tempo histórico. É a partir desse nome legalmente validado que podemos ser designados socialmente, mesmo que à nossa revelia. Esse funcionamento linguístico 
Bethania

Mariani

e social mostra tanto o aspecto convencional do nome próprio quanto implica seu caráter referencial, produzindo um efeito de identidade por sua repetição. $O$ nome próprio funciona como uma referência para o sujeito, uma vez que o sujeito é designado e se designa a partir desse nome que lhe é dado ao nascer. Mas esse processo linguístico funcionaria sempre sem produção de efeitos de significação?

Filósofos e lógicos, visando diferenciar o nome próprio do nome comum, acentuam seu aspecto indicial, essa forma linguística específica de identificar um sujeito. Identificação pessoal, identificação jurídica, classificação na família, na sociedade e na cultura, essas são funções do nome próprio. Um nome próprio não porta significado, razão pela qual não se traduz um nome próprio, ou seja, não há significado intrínseco, embora o nome próprio traga uma significação para aquele que o porta. Pais que falam línguas distintas muitas vezes escolhem um nome que seja bem parecido homofonicamente nas duas línguas justamente para que não seja necessário traduzi-lo.

Guimarães (2002), em seu minucioso estudo sobre o funcionamento semântico-enunciativo do nome próprio, observa que o acontecimento de linguagem em jogo - a nomeação legal - produz um efeito de unicidade a partir do momento em que essa atribuição de um nome próprio funciona identificando histórica e socialmente o sujeito em questão, unicidade entendida como produção de um efeito de colamento entre nome e pessoa. É o que permite ao Estado interpelar e responsabilizar esse sujeito no que o nome próprio carrega em termos das condições de produção em que se deu a nomeação, ou seja, da historicidade e da memória próprias ao acontecimento de linguagem (GUIMARÃES, 2002) que foi a nomeação em si. Isso não quer dizer, porém, que esse efeito de unicidade funcione de modo homogêneo, sem conflitos. Como afirma o autor, "nomear uma pessoa é uma enunciação que funciona por um processo de determinação semântico-enunciativa em virtude de se dar no interior do processo social de identificação, mas que, ao apagar, pela representação do enunciador, o lugar social de locutor, se mostra como meramente referencial" (p. 41).

Veremos a seguir uma outra forma de refletir sobre o nome próprio e a subjetivação; ou melhor, a constituição do sujeito. 


\section{Percursos: 2}

No percurso da psicanálise, Lacan, no seminário inédito A identificação (1961/62), introduz a questão do nome próprio na lição de 20 de dezembro. Inicialmente, o psicanalista apresenta os argumentos de Russel, Mill e Gardiner, para, em seguida, ao deslocar os argumentos dos lógicos e dos linguistas, situar o nome próprio em relação ao que ele chama de instância nomeadora, que é da ordem da letra, da função da letra no inconsciente. Letra, termo que em francês se diz lettre, palavra que guarda importante ambiguidade em sua homofonia: letra e carta. Desde meados dos anos 50 do século passado, nos seminários A carta roubada (1956) e Instância da letra no inconsciente, ou a razão desde Freud (1957), letra é termo com que Lacan designa, e segue conceituando ao longo de seu ensino, "alguma coisa" (expressão sua) que é determinante na estrutura psíquica do sujeito. Trata-se do suporte material do significante, enquanto que significante é uma entidade puramente relacional, cujo valor está em marcar diferenças fônicas em uma cadeia. A letra, explica-nos Nazar (2006), "é o circuito em torno do objeto impossível de ser apreendido pela rede de significantes, ela indica a estrutura 'como uma linguagem' do inconsciente. É por ela que o desejo pode ser lido e se fazer reconhecer" (p. 160). A letra, enquanto impossibilidade de representação por um significante, é o que faz furo no simbólico.

Tanto letra quanto significante não possuem significado em termos do aparelho psíquico. Nome próprio, portanto, tem a ver com essa "alguma coisa" mencionada: algo anterior à inscrição significante, algo que permite essa inscrição significante e que dá lugar ao registro de uma escrita. Podemos supor que Lacan está fazendo valer no nome próprio a inscrição de uma marca - o traço unário -, cujo funcionamento/ incidência será de um significante, marca distintiva. Pura marca distintiva no real, a ser contornada pelo Outro, ou seja, pelo Simbólico, e revestida por sentidos, pelo imaginário.

Em diferentes momentos dessa aula de dezembro de 1961 (e também na aula seguinte, de 10 de janeiro de 1962), encontramos perguntas: "O que é um nome próprio?" “O que é o nome próprio?" “Onde está o sujeito aí dentro?"

Na psicanálise, nome próprio tem a ver com o desejo do Outro, tesouro dos significantes, possibilidade de entrada na fala e na linguagem. A grafia de Outro com letra maiúscula é usada por Lacan para acentuar nossa inscrição e constituição como humanos no Simbólico, nas redes 
Bethania

Mariani

136

de significantes. Cadeia de significantes ou, como Lacan em vários de seus seminários e escritos designa, um lugar terceiro, o grande Outro. $\mathrm{O}$ corpo biológico de um recém-nato, enquanto puro real, para subjetivar-se se inscreve nesse Outro, sendo significantizado por aqueles que dele se ocupam para inscrevê-lo em uma novela familiar, em uma linhagem, em uma discursividade que permitirá o nascimento de um sujeito. 0 recém-nato, com seus movimentos, seu choro, seus sons que expressam necessidades do biológico, tem exatamente esses movimentos, choro e sons para ele retornados já significados por quem dele se ocupa. Quando falamos em subjetivação na psicanálise, referimo-nos a um "efeito de captura do corpo na linguagem" (LEBRUN, 2008, p. 30). Ou seja, está em jogo um processo de subjetivação, uma operação altamente complexa que humaniza o infans, aquele que ainda não fala, inserindo-o no simbólico e, por extensão, na lei e na cultura.

Assim, entrar na linguagem é entrar em redes significantes já instaladas e submetidas às leis da história, da cultura e de uma novela familiar específica. Dito de outra forma, na subjetivação há que se passar por uma transmissão que não é sem os significantes do Outro.

Lacan (1961) afirma que a entrada na linguagem produz uma marca de pertença e é marcada pela transmissão da falta. Ou seja, a entrada na linguagem é a entrada em uma cadeia significante que porta um furo, que não diz tudo, que não significa tudo. E é importante ressaltar: as ausências contam na cadeia significante: ela é não toda. Essa característica como não-toda porta um impossível: há um impossível de ser dito que, no entanto, insiste, resiste e retorna como enigma, causando estranhamento para quem fala. Referimo-nos, aqui, às formações do inconsciente, sobretudo aos chamados lapsos de linguagem, notadamente os chistes e os atos falhos.

Muitas vezes, de maneira marcadamente enigmática, esses lapsos de linguagem recaem sobre nosso nome próprio, sinalizando que algo se passa no inconsciente do sujeito. Por exemplo: às vezes ao dizermos nosso nome próprio não somos compreendidos por quem nos escuta; ou ainda, às vezes precisamos soletrar, insistir numa determinada forma linguística; às vezes, ainda, descobrimos anagramas em nosso nome, fazendo deslizar sentidos anteriormente atribuídos na novela familiar; e mais, às vezes nos damos conta de alguma característica em nosso nome que não se repete (ou, ao contrário, que se repete) nos nomes dos demais membros da família. E assim vai. Freud e Lacan narram inúmeros 
casos de esquecimentos, apelidos e marcas variadas que fazem parte da historicidade inconsciente que a letra nome próprio registra.

Como compreender o funcionamento do inconsciente na relação com o próprio do nome próprio? À pergunta "quem sou eu", Lacan responde com a falta no campo do Outro de um significante que diga tudo desse sujeito e aponta para a "dependência da formação do sujeito em relação à existência de efeitos do significante como tal" (LACAN, lição de 20 de dezembro de 1961). Em outras palavras, seria um nome dado um nome próprio? Seria o nome próprio um destino para o sujeito?

Se o nome próprio é um significante que o sujeito pode usar para se representar, esse mesmo nome próprio não tem como significar totalmente o sujeito, pois se encontra na dependência de alguma coisa que se constitui como falta em uma temporalidade e em uma lógica que Nome próprio e constituição do sujeito são de outra ordem. Enquanto capturado em "efeitos do significante" do Outro, o nome próprio designa aquele que fala, mas é pouco legível.

Melhor dizendo: na anterioridade do nome próprio, antes mesmo que o infans diga "eu", há a inscrição de um traço com o qual e a partir do qual o sujeito se identifica e que, de alguma maneira, escreve seu próprio nome, permitindo que se produza uma escrita a partir daí. Nesse seminário realizado entre 1961 e 1962, partindo do que Freud ${ }^{1}$ discute sobre identificação, Lacan nomeia esse traço como einziger zug: traço unário, traço a partir do qual se viabiliza a escrita de S1, o significante unário, significante que inaugura a cadeia e que fica recalcado para o sujeito. Ele se escreve como significante de uma falta de significante no campo do Outro. Escrita que repete incansavelmente essa falta e as tentativas do sujeito em escrever essa falta. $O$ inconsciente é letrado.

Como afirma Ballans (2007), zug é uma palavra que porta um sentido de marcha, um andar que dá passagem a um cortejo, deixando traços, marcas de um traçado. "Rastro de um traço", diz-nos Lacan, rastro desse traço unário ou desse "significante solitário" - único, unitário e unificante - que possibilita o suporte, lugar material da diferença entre significantes, e que é fundamental para a representação do sujeito no desejo do Outro.

Diz Lacan (1961): “Inscrição de lugar inaugural para onde o sujeito sempre retorna em sua ignorância errante. [...] algo que se pode

1 Em Psicologia das massas e análise do ego, Freud diz que a identificação "é a mais remota expressão de um laço emocional com outra pessoa." (p. 115). 
procurar relativamente ao sujeito antes mesmo que ele faça uso de seu nome." E Lacan segue afirmando: aí se encontra a "função significante: função de amarração, ancoragem para o sujeito". Para o sujeito em sua relação, "em sua referência ao significante".

Quando se diz "eu", o nome próprio fica subdito. Fica subdito, sobretudo, um rastro de traço que vai organizar o inconsciente: "não pode haver definição de nome próprio senão na medida em que nós nos apercebemos da relação da emissão nomeadora com algo que, em sua natureza radial, é da ordem da letra". Significante - corpo material sutil - e leBethania tra- "suporte material do significante" -, eis aqui a tensão entre o que se Mariani tenta fazer ler e ouvir e o que o significante não tem como representar.

Esse é um ponto importante: "Mesmo vindo de um Outro" - dos efeitos do significante do Outro -, o nome próprio constitui o núcleo daquilo que vivo como sendo "Eu". Ao fazer uso de seu nome próprio, subdizendo em seu nome a "gênese" do modo como se transmitiram a subjetivação e também as identificações, o sujeito se singulariza, se ancora, se marca em sua diferença significante. E aí se marca a divisão do sujeito: entre um "eu" pronome que uso para falar, que me faz supor uma autonomia, que me faz supor dona do meu próprio dizer, e um Outro que fala em mim de modo pontual e surpresivo. Essa divisão subjetiva é estrutural e constitutiva da subjetivação, conforme a psicanálise.

Façamos duas pausas.

Como é teorizada a noção de sujeito na psicanálise? Sujeito em um sentido estrutural, topológico, e não psicológico (como unidade de uma interioridade): é do sujeito do inconsciente o de que se trata. $\mathrm{O}$ sujeito do inconsciente não é redutível ao sujeito falante. Naquele que fala e tropeça na linguagem, há sempre ali, enquanto constitutivo de seus tropeços, um terceiro, o grande Outro, suporte e testemunha da posição do sujeito do inconsciente.

E como é teorizada a noção de significante? É significada como o que representa o sujeito para outro significante.

Sigo na companhia de alguns fragmentos textuais de Lacan que já tive a oportunidade de citar em outros momentos. São fragmentos que contribuem na conceituação de significante, de sujeito e de inconsciente e ajudam a situar que o que a psicanálise propõe situa-se em outro lugar teórico. Deslocamentos precisam ser realizados.

Para Lacan (1998), o inconsciente é estruturado como uma linguagem, funciona à moda de uma linguagem. Remete ao “jogo combinatório 
operando sozinho - é esta estrutura que dá seu estatuto ao inconsciente" (p. 26). Para haver sujeito do inconsciente, há que haver a inscrição de uma cadeia significante no modo como Lacan a pensa: "anéis cujo colar se fecha no anel de um outro colar feito de anéis", encontrando-se, assim, na cadeia "a ordem das invasões constitutivas do significante" (p. 505) que se manifesta nos atos falhos, nos chistes. E "O que a estrutura da cadeia significante revela é a possibilidade que eu tenho, justamente na medida em que sua língua me é comum com outros sujeitos, isto é, em que essa língua existe, de me servir dela para expressar algo completamente diferente do que ela diz" (p. 508, grifo nosso).

Estamos no seguinte ponto: se é do sujeito do inconsciente o de que se trata, isso aponta para o fato de que, para além do sujeito da gramática (no caso, um shifter, o pronome pessoal "eu"), marca-se uma

Nome próprio e constituição do sujeito divisão com a presença de um outro sujeito, pontual e evanescente, que comparece com sua própria enunciação. E esse outro sujeito, que comparece sem ser convidado, fala à revelia e, com isso, provoca efeitos de retração, ou seja, é na temporalidade de um "só-depois" que nos damos conta de que esse sujeito do inconsciente se manifestou. Ele não é antecipável e, ao se manifestar, formula um enigma, que expressa uma verdade com aquele pouco de sentido que ali se materializa. Esse outro sujeito, com seus enigmas, nos faz rir, "parece feliz em se exprimir", como é o caso dos chistes, ou nos deixa embaraçados, como no caso dos lapsos (MELMAN, 2009, p. 17).

Lacan assim define o que se passa no momento em que esse outro sujeito, com seus enigmas, comparece:

Tropeço, desfalecimento, rachadura. Numa frase pronunciada, escrita, algo se estatela. [...] Ali, alguma outra coisa quer se realizar - algo que aparece como intencional, certamente, mas de uma estranha temporalidade. 0 que se produz nessa hiância no sentido pleno do termo produzir-se, se apresenta como um achado. [...] Um achado que é, ao mesmo tempo uma solução - não forçosamente acabada, mas, por mais incompleta que seja, tem esse não-sei-o-quê que nos toca [...] a surpresa - aquilo pelo que o sujeito se sente ultrapassado, pelo que ele acaba achando ao mesmo tempo mais e menos do que esperava - mas que de todo modo, é, em relação ao que ele esperava, de um valor único. Ora, esse achado, uma vez que ele se apresenta, é um reachado, e 
Bethania

Mariani

140

O que comparece como perda para o sujeito é estruturalmente constitutivo como marca da falta do significante inaugural. Dele só se tem o rastro do traço, o que possibilitou o traçado, a escrita do significante em sua função de representar o sujeito para outro significante.

Retornemos ao nome próprio. E às noções de letra e einziger zug.

Como vimos, o nome próprio é um tipo de nome específico e pode ter valor significante no inconsciente, ou seja, pode ser tomado como significante. Lembremos aqui do esquecimento de Signorelli, esquecimento do próprio Freud e por ele narrado em Psicopatologia da vida cotidiana, e retomemos a forma como Lacan analisa esse lapso de linguagem. A partir da análise freudiana, a partir dos restos significantes de linguagem que Freud enumera em seus laços associativos, Lacan depreende Sig, um apelido de Freud dado por sua mãe, marcando aí o traço significante do nome próprio Sigmund na série metonímica signor...her... herr...signorelli, o nome esquecido. Se, para Freud, o esquecimento de Signorelli (nome próprio do pintor italiano que fez os afrescos da catedral de Orvietto) aponta para o recalcamento de lembranças desagradáveis (a morte por suicídio de um paciente de Freud que sofria de impotência sexual), para Lacan, o significante recalcado é Sig, que, sem possibilidade de ser substituído, é o tal apelido do Freud. Assim, aquilo em que Freud não quer pensar é sua própria velhice e proximidade da morte. ${ }^{2}$

Sig, como diminutivo de um nome próprio, cumpre a função de representar e designar o sujeito no laço social, como indicativo de uma identidade no laço social. O sujeito do inconsciente ali se vê convocado, em suas associações, ou seja, em suas tentativas de representação de um significante para outro, a tentar resolver o enigma do esquecimento de um nome próprio no qual um traço de seu nome se encontra representado. Sig tem uma função significante: é um significante insubstituível na medida em que nele está inscrita a identificação primeira (e unificante) do traço unário que suporta esse nome próprio. Um nome próprio singular e específico em sua diferença única e primordial em cada sujeito.

2 Em Freud (1921) e em Mariani (2012) encontra-se uma discussão mais alongada do esquecimento de Signorelli. 


\section{Referências}

BALLANS, P. L'écriture blanche: un effet du démenti pervers. Paris: L'Harmattan, 2007.

FREUD, S. Psicologia das massas e análise do ego (1921). In: Obras completas. Rio de Janeiro: Imago, 1969. v. 18.

GUIMARÃES, E. Semântica do acontecimento. Campinas: Pontes, 2002.

LACAN, J. Escritos. Rio de Janeiro: J. Zahar, 1998.

Nome próprio e constituição do sujeito

A identificação (1961-1962). Recife: Centro de Estudos Freudianos do Recife (Publicação não comercial), 2003.

LEBRUN, J.-P. A perversão comum; viver juntos sem o Outro. Rio de Janeiro: Companhia de Freud, 2008.

MARIANI, B. O esquecimento na memória. In: ROMÃO, L. M. de S.; CORREA, F. S. (Org.). Conceitos discursivos em rede. São Carlos: Pedro \& João, 2012. p. 153-174.

MELMAN, Charles. Para introduzir à psicanálise nos dias de hoje. Porto Alegre: CMC, 2009.

NAZAR, T. O escrito da escrita. In: MARIANI, B. (Org.). A escrita e os escritos: reflexões em análise do discurso e psicanálise. São Carlos: Claraluz, 2006. p. 7-12.

SARAMAGO, J. Pequenas memórias. Rio de Janeiro: Companhia das Letras, 2006.

SOLLER, C. Lacan, o inconsciente reinventado. Rio de Janeiro: Companhia de Freud, 2012. 